\title{
A note of caution on the Knockout Mouse Project
}

\section{To the editor:}

I read with interest the position papers advocating the generation of mice with mutations in all known genes ${ }^{1,2}$. As a researcher who has long been active in this area, I would like to voice some caution on financial, logistical and scientific grounds. Financially, at a time of tightening budgets, this approach could be sustained only by chipping away at the dwindling pool of investigator-initiated grants to feed a 'military-industrial' behemoth of sorts that will attend to the task. Logistically, I take mild issue with the notion that this resource would be either widely useful or readily available. Many of the 415 targeted mutant strains deposited at the Jackson Laboratory have been frozen for lack of takers. If this is any indication of what's to come, I am not sure that the demand will justify the effort. Scientifically, I challenge the notion that we need to standardize methods to generate null alleles. I can think of many instances in which different null alleles of the same gene generated in different laboratories have resulted in different phenotypes and thus taught us important lessons about gene function. I also argue that shotgun phenotyping for a limited set of parameters, as proposed by the two groups, is unlikely to yield much useful information. Most of the common tests likely to be used measure traits under polygenic, genetically heterogeneous control, and thus, only large effects are likely to be detected. Although I support the creation of a mechanism to facilitate the generation of knockout mice, I suggest that we use some caution before embarking on an endeavor as sweeping as that advocated by my colleagues.

\section{Domenico Accili}

Columbia University College of Physicians \& Surgeons, Naomi Berrie Diabetes Center, Department of Medicine, 1150 St. Nicholas Avenue, New York, New York 10032, USA. Correspondence should be addressed to D.A. e-mail:da230@columbia.edu

1. The Comprehensive Knockout Mouse Project Consortium. Nat. Genet. 36, 921-924 (2004).

2. The European Mouse Mutagenesis Consortium. Nat. Genet. 36, 925-927 (2004). 